\title{
Thermal Structure of Subducting Slab along the Java Arc and Its Significance to the Volcanoes Distribution
}

\author{
Lina Handayani \\ Research Center for Geotechnology, LIPI \\ Email: lina.handayani@gmail.com
}

\begin{abstract}
Java Island has a unique tectonic features and one of it is the pattern of the volcano distribution along the island. The volcano pattern occurrence might be connected to the deeper process of geodynamic. Hence, thermal structure modeling is employed to find any association between the subducting plate and the tectonic of the overriding plate. Thermal structure of a subducting plate depends on the age of the lithosphere and the dip of the subduction. With the lithospheric age increases from west to east of Java, varies from about 90 my to 120 my old, there are dissimilarities in thermal structure models. The comparison with volcanoes positions shows that differences of thermal structure might have associated to variation in the formation of volcanoes in Java Island.
\end{abstract}

Keywords: Java arc; subducting slab; island arc tectonic; thermal structure; volcano.

\section{$1 \quad$ Introduction}

Java Island is a part of Sunda Arc subduction system that is elongated from North of Sumatra to Banda Sea. Nevertheless, Java Island has its own unique feature compared to other part of the island arc in this subduction system. For instance, Sumatra has a long fault system while Java has a more complicated one. So does the volcanic pattern along Java Island is not as simple as volcanic line along Sumatra. Therefore, we are motivated to analyze the characteristic of Java from subduction system point of view.

The Indo-Australian plate is subducting beneath Eurasian plate perpendicularly with estimated convergence rate of $67 \pm 7 \mathrm{~mm} / \mathrm{yr}$ [1] along the Java arc with dip about $60 \mathrm{o}$ and the deepest earthquake record is about $670 \mathrm{~km}$ beneath the Java Sea [2]. The age of ocean floor along the Java Arc from Sunda Strait to the eastern end of Java increases from 80 my to 140 my (Figure 1, [3]). Other than the dip and age of the subducting slab, there is no apparent other differences in physical properties of the slab. However, tomography study indicates different seismic wave properties along the east-west direction of the island with an evident seismic gap at central Java region [4].

Received February 12th, 2010, Revised May 24th, 2010, Accepted for publication May 25th, 2010. 


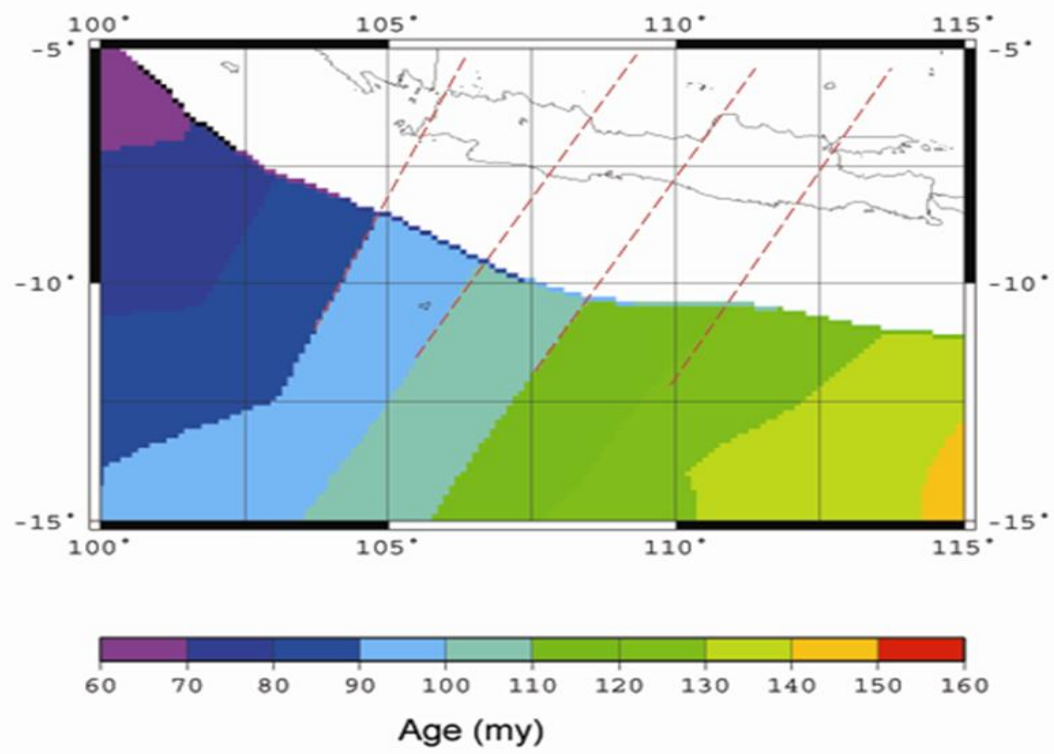

Figure 1 Lithospheric age of the Indo-Australian subducting plate at the Java Subduction Zone (data source: Müller, et al. [3]).

Thermal structure modeling of subducting slab is employed to characterize the slab beneath the Java region. The thermal structures model then might assist us in understanding the differences on magma generation process, which is responsible to the volcanism activity along the island arc. Ponko and Peacock [5] with their thermal modeling had associated the temperature of the subducting slab and the characteristic of magma from volcanic arc of Alaska. Furthermore, Green [6] suggested that thermal structure of the underlying subduction zone influenced the melting process of mantle wedge, which then resulted in different basalt chemistry of igneous rock along Garibaldi volcanic belt. This paper presents an effort of finding such relationship. Even though the result is not as definite as had been expected, but it indeed offers the possible association.

\section{$2 \quad$ Method and Result}

When the relatively cold subducting slab is entering the hot mantle, it is continuously getting warmer as it descends and adapts to the surrounding mantle material. On this research, the temperature is calculated as a function of the depth in the slab and time since subduction. With assumption that the mantle temperature is $1400^{\circ} \mathrm{C}$ and the temperature of the top of the slab at the time of penetration into the mantle is $600^{\circ} \mathrm{C}$, the mean temperature for each 
stage (time) is calculated (see the model sketch in Figure 2). The slab is assumed to have a uniform thermal diffusivity ( $\kappa)$.

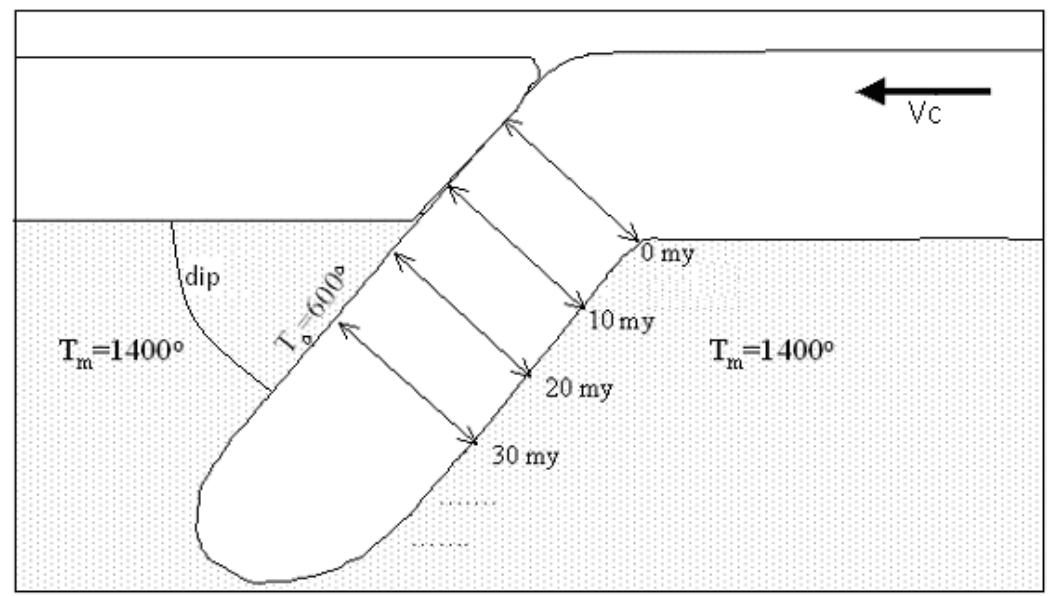

Figure 2 Sketch of subducting plate model. ( $V c$ is the convergence rate, describes the direction of the slab movement)

The thermal modeling is approached as the cooling of half-space problem [5] [7]. The slab is assumed to have a uniform temperature initially, then its surface is suddenly given a different temperature at $t=0$ and remained at that for the rest of time. Temperature of slab is approximated as a one-dimensional column by ignoring variations horizontal diffusion of heat. The top of the slab initially has the lowest temperature $\left(T_{s}\right)$ as it came from the surface while the bottom of the slab has the highest $\left(T_{M}\right)$ as it always has contact with the mantle. The hot mantle above the slab functions as the source of the heat to increase the temperature of the slab.

The temperature is calculated from $z=0$ to $z=L$, where $L$ is the thickness of the slab. The thermal conduction equation can be represented as Fast Fourier Transform equation [7] [8], which illustrates the distribution of heat (or variation in temperature, $T)$ in a given distance $(z)$ over time $(t)$. Time variable, $t$, is the amount of time that has passed since the column was at point where it started to descend (i.e. the trench). At any point in time, the thermal function $T$ can be represented as the discrete Fast Fourier Series.

$$
T(z, t)=\sum_{j=0}^{N}\left[a_{j}(t) \cos \left(k_{j} z\right)+b_{j}(t) \sin \left(k_{j} z\right)\right]
$$


The $k_{j}$ are the wave-number of the wave functions:

$$
k_{j}=\frac{2 \pi j}{L}
$$

where $j$ is the number of intervals used in the calculation. The amplitudes are given by:

$$
a_{j}(t)=a_{j}(0) e^{-k_{j}^{2} k t}
$$

and

$$
b_{j}(t)=b_{j}(0) e^{-k_{j}^{2} k t}
$$

The thickness of the slab $(z)$ is the thickness of the plate on the trench boundary, which can be represented as the thickness of thermal boundary layer. From the same approach (half-space cooling problem), we can derive the equation of relationship between the thickness of thermal boundary layer and the thermal diffusion distance $(\sqrt{\kappa t})$. Subsequently, we can calculate the thickness of the slab based on the age of the ocean floor [7]:

$$
\text { thickness }=2.26 \sqrt{\pi \kappa(\text { age })}
$$

where $\kappa$ is thermal diffusivity $\left(=10^{-6} \mathrm{~m}^{2} \mathrm{~s}^{-1}\right)$. Using the slab thickness of the Java subducted slab that was derived from the age of the lithosphere (Table 1), the temperature distribution of each stage is calculated. Each stage is represented by an arrow line within the slab sketch (Figure 2). The model on each stage is divided into $128\left(2^{6}\right)$ movements. Figure 3 shows an example of temperature calculated for five stages descend of a slab.

Table 1 Lithospheric thickness calculated from the magmatic age.

\begin{tabular}{ccc}
\hline Region & $\begin{array}{c}\text { Age } \\
(\mathbf{m y})\end{array}$ & $\begin{array}{c}\text { Thickness } \\
(\mathbf{k m})\end{array}$ \\
\hline A & 90 & 67.54 \\
B & 100 & 71.19 \\
C & 110 & 74.66 \\
D & 120 & 77.98 \\
\hline
\end{tabular}




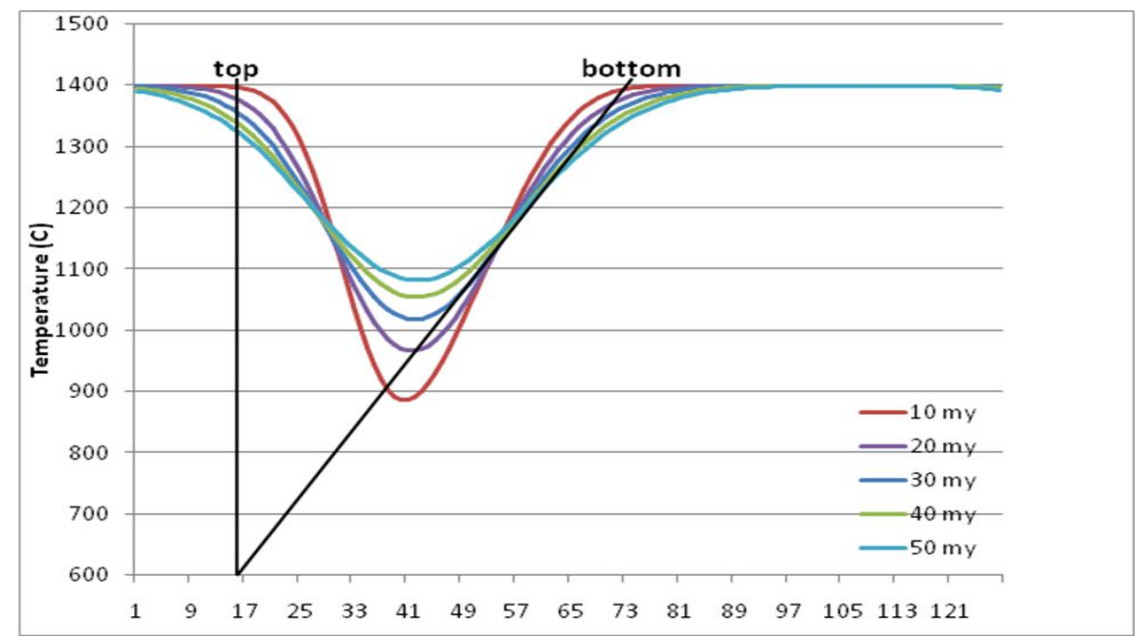

Figure 3 Temperature distribution variation by age (in million years) from top to bottom of the perpendicular section of the slab. The black bold lines are the initial condition.

The temperature for each stage (those 128 numbers) is then averaged to obtain the mean temperature of that stage. Therefore, we have a series of mean temperatures that reflect every stage of descend of a subducting slab. The procedure is then applied to four different thicknesses of slabs. The result of thermal variation along the four types of subduction slabs is presented in Figure 4. The figure shows the variation of the temperature for 90, 100, 110 and 120 my age of lithosphere.

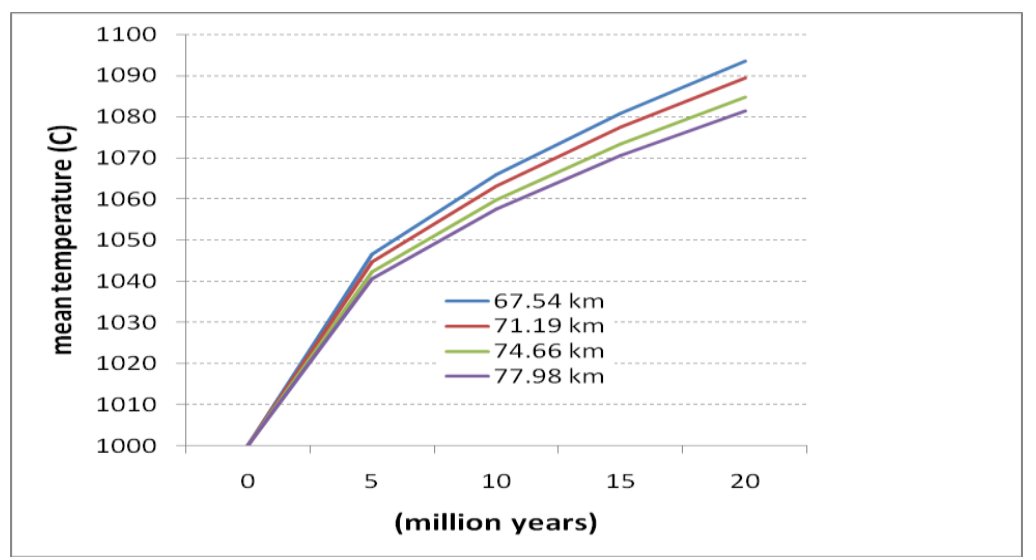

Figure 4 Mean temperatures of four different thickness of slabs from 0 to 20 million years of subduction. 


\section{Discussion}

A partial melting of descending slab and the overlying asthenosphere is one possible origin of a volcano. The partial melting occurs at a certain temperature and pressure where subducting slab reaches a depth more than $80 \mathrm{~km}$ [9]. Therefore, temperature of the subducting plate should be an important factor that influenced the formation of a volcano. According to the subducting slab model as shown in Figure 4, there should be some dissimilarities in volcanoes distribution along Java Arc. At least, the distance from the axis of trench should be varied. Assuming that a similar temperature is needed to create a volcano, that certain temperature will be reached on different rate, where the youngest slab (the least thick) would reach it first and the oldest (the thickest) would be the last. If the dip of subducting plate is uniform along the Java Arc, the volcanoes at the west of Java should be closer to the trench than the volcanoes at the east of Java.

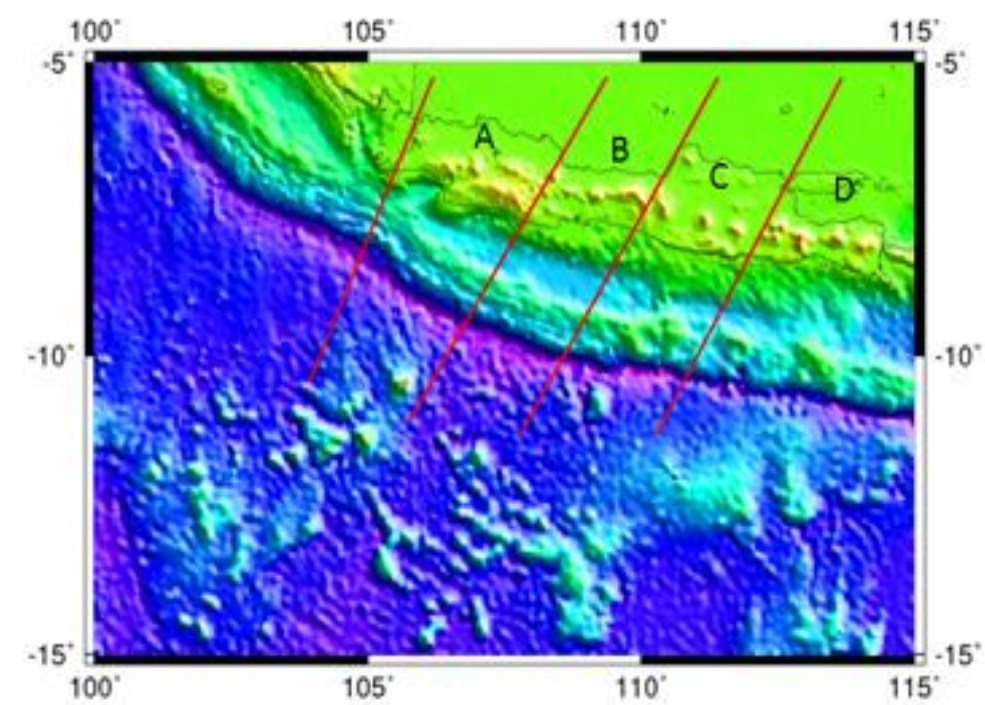

Figure 5 Topography map of Java showing volcanic cones with red lines grouped them based on the age contour lines from Figure 1. (Topography data source: Smith \& Sandwell [10].

Figure 5 shows the distribution of volcanoes along Java Island (yellow cones) divided into 4 groups based on the age of the oceanic floor subducting beneath. Names of those volcanoes are listed in graph (Figure 6) that also shows the depth of the Benioff zone beneath each of the volcano. The distance from the trench axis to the volcanic line of group $\mathrm{A}$ is about $241 \mathrm{~km}$, to the volcanoes of group B are between 301 and $326 \mathrm{~km}$, to the volcanoes of group C between 278 
- $289 \mathrm{~km}$ and to the volcanoes of group D about $289 \mathrm{~km}$. With exception of group $\mathrm{B}$, the volcanoes at the east are indeed farther from the trench than the ones at the west.

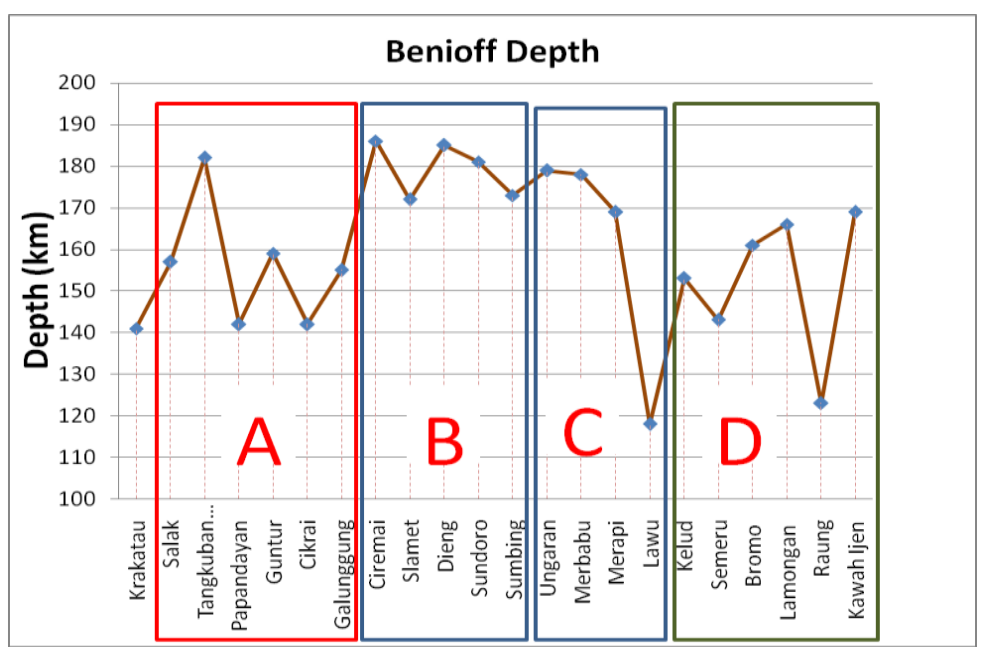

Figure 6 Four groups of volcanoes of Java separated by lines (as in Figure 5) on the graph of Benioff's depth underneath each of the volcano. (Data source: Huthcison [11]).

Based on the Benioff graph, the volcanoes can be classified into three groups, with B and C are merged. Group A, with one exception (G. Tangkubanparahu), has Benioff depth between 140 and $160 \mathrm{~km}$. Group B \& C, also with one exception (G. Lawu), has Benioff depth between 170 and $190 \mathrm{~km}$. And Group D, except G. Raung, has Benioff depth between 140 and $170 \mathrm{~km}$.

Those horizontal and vertical distance analyses demonstrate the possibility of subducting slab thermal structure influence toward the formation of volcanoes. Exception of most volcanoes in the central Java might be associated to the seismic gap state, which is linked to the condition of colliding plates [4]. However, the exact relationship needs further studies involving the detail characteristics of each volcano (i.e. geochemistry and petrology studies) that have direct relation to thermal processes.

\section{Conclusion}

Thermal structure models of beneath Java subducting slab indicate different conditions of slab's thermal distribution that were calculated based on the thickness of the subducting oceanic lithosphere. These thermal structure differences might have contributed to variation in distances of volcanoes in Java 
Island, horizontally from the trench axis and vertically from the subducting slab (Benioff zone). Further studies are needed to elucidate the cause and effect of the subducted slab thermal properties toward volcanoes formations.

\section{References}

[1] Tregoning, P., Brunner, F.K., Bock, Y., Puntodewo, S.S.O., McCaffrey, R., Genrich, J.F., Calais, E., Rais, J. \& Subarya, C., First geodetic measurement of convergence across the JavaTrench, Geophys. Res. Lett., 21, pp. 2135-2138, 1994.

[2] Newcomb, K.R. \& McCann, W.R., Seismic history and seismotectonics of the Sunda Arc, J. Geophys. Res., 92, pp. 421—439, 1987.

[3] Müller, R.D., Roest, W.R., Royer, J.-Y., Gahagan, L.M., and Sclater, J.G., A digital age map of the ocean floor, SIO Reference Series, Scripps Institution of Oceanography, pp. 93-30, 1997.

[4] Widiyantoro, S., Harjono, H., Lianto, F., Fauzi \& Wandono, Seismisitas dan struktur kecepatan gelombang seismik di sepanjang Pulau Jawa, Prosiding HAGI, Yogyakarta 2004.

[5] Ponko, S \& Peacock, S.M., Thermal modeling of the southern Alaska subduction zone: Insight into the petrology of the subducting slab and overlying mantle wedge, J. Geophys. Res., 100(B11), pp. 22117 - 22128, 1995.

[6] Green, N.L., Influence of slab thermal structure on basalt source regions and melting conditions: REE and HFSE constraints from the Garibaldi volcanic belt, northern Cascadia subduction system, Lithos, 87, pp. 2349, 2006.

[7] Turcotte, D.L. \& Schubert, G., Geodynamics. Applications of Continuum Physics to Geological Problems, John Wiley \& Sons, pp. 450, 1982.

[8] Press, W.H., Flannery, B.P., Teukolsky, S.A., Vetterling, W.T., Numerical Recipes. The Art of Scientific Computing, Cambridge Univ. Press, pp. 818, 1988.

[9] Kearey P. \& Vine, F.J., Global Tectonics, $2^{\text {nd }}$ ed., Blackwell Science, pp. 333, 1996.

[10] Smith, W.H.F., \& Sandwell, D.T., Global seafloor topography from satellite altimetry and ship depth soundings, Science, 277, pp. 1957$1962,1997$.

[11] Hutchison, C.S., Indonesia, Andesites, Thorpe, R.S. (ed), John Wiley \& Sons, pp. 207-224, 1982. 